\title{
The Gap between Evidence-based Guidelines and Daily Practice: Reply to Letter
}

\author{
Gerwin A. Bernhardt
}

Published online: 25 February 2010

(C) Société Internationale de Chirurgie 2010

We thank Dr. Slim for his comments on our paper [1] and for his agreement with our results [2]. The mentioned "French touch" in his letter is an explanation for two conflicting guidelines. If all guidelines were based on evidence-based medicine (EBM) criteria and regularly revised, I guess they would not conflict when dealing with the same topic. This describes another problem where there is a gap between evidence-based guidelines and daily practice. On the one hand, there are not-up-to-date eminence-based medicine guidelines that are not based on EBM criteria, and, on the other hand, existing guidelines based on EBM criteria, like the current guidelines of the European Hernia Society (EHS) [3], are hardly followed in daily practice. The attitude of ignoring EBM guidelines in favor of eminence-based medicine seems to be neither a local Austrian nor a French problem but probably broadly reflects what is going on elsewhere in Europe as outlined by Dr Holzheimer in his commentary [4].

The reasons for the high number of laparoscopic hernia repairs in continental Europe are miscellaneous. First, I think Dr. Slim is right in saying that laparoscopic surgery originated in Europe. Second, there is strong technical support from laparoscopic industry in Europe. Third, Europe has many experts with high personal experience and a concomitant high case load. This high level of experience along with the high quality of surgery and low complication and recurrence rates is especially expressed in the EHS guidelines in which endoscopic surgery is preferred, even for primary hernias if expertise is present [3]. Finally,

\section{G. A. Bernhardt $(\square)$}

Division of General Surgery, Department of Surgery, University

Clinic Hospital, Medical University Graz, Auenbruggerplatz 29, 8036 Graz, Austria

e-mail: gerwin.bernhardt@klinikum-graz.at
Europe has excellent training facilities for young surgeons, including virtual reality for laparoscopic surgery that is better than open surgery $[5,6]$. In this context, I cannot agree with Dr. Slim's concern that laparoscopic surgery will not be performed by the next generation of surgeons. Moreover, with the number of laparoscopic procedures increasing, we can expect that the currently higher costs compared to open surgery might decrease which will result in a significant upturn in the number of laparoscopic procedures.

To conclude, I agree with Dr. Slim "that it is some kind of wisdom to know the benefits and limits of laparoscopic repair" [7], and just because of that, "wise surgeons" would rely on actual EBM guidelines, for instance the guidelines of the EHS [3].

\section{References}

1. Bernhardt GA, Kornprat P, Cerwenka H et al (2009) Do we follow evidence-based medicine recommendations during hernia surgery? Results of a survey covering 2441 hernia repairs in 2007. World J Surg 33:2050-2055

2. Slim K (2010) The gap between evidence-based guidelines and daily practice. World J Surg 34:000-000. doi:10.1007/s00268-0090367-x

3. Simons MP, Aufenacker T, Bay-Nielsen M et al (2009) European Hernia Society guidelines on the treatment of inguinal hernia in adult patients. Hernia 13:343-403

4. Holzheimer RG (2009) Inguinal hernia repair: What to do with the evidence? World J Surg 33:2056-2057

5. Seymour NE (2008) VR to OR: a review of the evidence that virtual reality simulation improves operating room performance. World J Surg 32:182-188

6. Gurusamy K, Aggarwal R, Palanivelu L et al (2008) Systematic review of randomized controlled trials on the effectiveness of virtual reality training for laparoscopic surgery. Br J Surg 95:1088-1097

7. Slim K, Chipponi J (2006) Laparoscopic surgery today. Br J Surg 93:779-780 